\title{
Quantifying the effect of seasonal and vertical habitat tracking on planktonic foraminifera proxies
}

\author{
Lukas Jonkers and Michal Kučera \\ MARUM, Universität Bremen, Leobenerstraße 8, Bremen, Germany \\ Correspondence to: Lukas Jonkers (ljonkers@marum.de) \\ Received: 24 November 2016 - Discussion started: 5 December 2016 \\ Accepted: 3 May 2017 - Published: 6 June 2017
}

\begin{abstract}
The composition of planktonic foraminiferal (PF) calcite is routinely used to reconstruct climate variability. However, PF ecology leaves a large imprint on the proxy signal: seasonal and vertical habitats of PF species vary spatially, causing variable offsets from annual mean surface conditions recorded by sedimentary assemblages. PF seasonality changes with temperature in a way that minimises the environmental change that individual species experience and it is not unlikely that changes in depth habitat also result from such habitat tracking. While this behaviour could lead to an underestimation of spatial or temporal trends as well as of variability in proxy records, most palaeoceanographic studies are (implicitly) based on the assumption of a constant habitat. Up to now, the effect of habitat tracking on foraminifera proxy records has not yet been formally quantified on a global scale. Here we attempt to characterise this effect on the amplitude of environmental change recorded in sedimentary PF using core top $\delta^{18} \mathrm{O}$ data from six species. We find that the offset from mean annual near-surface $\delta^{18} \mathrm{O}$ values varies with temperature, with $\mathrm{PF} \delta^{18} \mathrm{O}$ indicating warmer than mean conditions in colder waters (on average by $-0.1 \%$ (equivalent to $0.4{ }^{\circ} \mathrm{C}$ ) per ${ }^{\circ} \mathrm{C}$ ), thus providing a firstorder quantification of the degree of underestimation due to habitat tracking. We use an empirical model to estimate the contribution of seasonality to the observed difference between PF and annual mean $\delta^{18} \mathrm{O}$ and use the residual $\Delta \delta^{18} \mathrm{O}$ to assess trends in calcification depth. Our analysis indicates that given an observation-based model parametrisation calcification depth increases with temperature in all species and sensitivity analysis suggests that a temperature-related seasonal habitat adjustment is essential to explain the observed isotope signal. Habitat tracking can thus lead to a signifi-
\end{abstract}

cant reduction in the amplitude of recorded environmental change. However, we show that this behaviour is predictable. This allows accounting for habitat tracking, enabling more meaningful reconstructions and improved data-model comparison.

\section{Introduction}

The chemical composition of planktonic foraminifera shells reflects the environmental conditions in which they precipitate and fossil shells serve as the prime source of information about the past state of the oceans. Planktonic foraminifera species are non-uniformly distributed across the world ocean, indicating they inhabit distinct ecological niches (Bé and Tolderlund, 1971). Indeed, habitat preferences are routinely used for palaeoenvironmental reconstruction based on fossil foraminifera assemblages. However, these habitat preferences also affect reconstructions based on single species. Since planktonic foraminifera inhabit a wide vertical range of the water column and often show distinct variability in their seasonal abundance (e.g. Field, 2004; Tolderlund and Bé, 1971; Fairbanks et al., 1980; Jonkers et al., 2010, 2013; Deuser et al., 1981), it is well known that, rather than reflecting annual mean surface conditions, the average proxy signal in sedimentary planktonic foraminifera is weighted towards conditions at the depth and season of calcification (Mix, 1987). While species-specific seasonality and calcification depth are often taken into account, it is often implicitly assumed that both remain constant in time and space. This assumption is at odds with observations from the presentday ocean, which likely has important implications for re- 


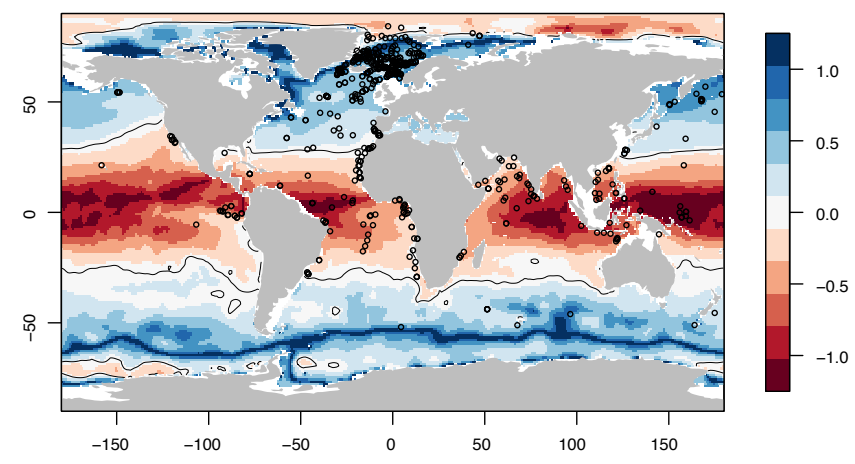

Figure 1. Distribution of core top $\delta^{18} \mathrm{O}$ data used in this study. Background colours represent the $\log _{10}$ ratio of the temperature range at the surface to the temperature range in the annual mean values between 0 and $200 \mathrm{~m}$ depth. Blue colours indicate areas where seasonal temperature gradients are larger than vertical gradients and red colours indicate the opposite. The thin black contour line shows the zero level of this ratio.

constructions of climate change and proxy calibrations based on core top data.

Plankton tow and sediment trap studies have shown large variability in the phenology within individual planktonic foraminifera species (e.g. Tolderlund and Bé, 1971; Zaric et al., 2005). A recent review demonstrated that this variability is widespread and follows a predictable pattern consistent with the concept that foraminifera (passively) track their optimum habitat (Jonkers and Kučera, 2015). Two broad ecological groups with different seasonality patterns were found; outside the tropics, warm-water species narrow their occurrence into the season of maximum temperatures. The seasonality in cold-water species also shows a clear relationship with near-surface temperature as their flux peak generally occurs earlier in the year in warmer waters (Jonkers and Kučera, 2015). While the latter trend appears to be driven by the timing of food availability rather than by temperature, both patterns have the same effect on the fossil record since they reduce the amplitude of (temperature) change that bulk samples of their fossil shells will reflect.

The depth habitat of planktonic foraminifera species also shows clear variability in space and time (Field, 2004; Fairbanks and Wiebe, 1980; Schiebel et al., 2001; Peeters and Brummer, 2002; Rebotim et al., 2017). Food and light availability, (thermal) stratification and temperature have all been suggested to be potential drivers of the vertical distribution of planktonic foraminifera (Schiebel et al., 2001; Fairbanks and Wiebe, 1980; Ortiz et al., 1995; Salmon et al., 2015; Fairbanks et al., 1982). In contrast to seasonality a global overview is lacking and the exact controls on depth habitat variability within species remain poorly constrained. The issue of changing depth habitat is further complicated by the tendency that many foraminifera likely migrate in the water column during their life and add proportionally more calcite at later stages in their life, potentially resulting in a mismatch between depth habitat and calcification depth (e.g. Duplessy et al., 1981). Whereas depth habitat can be directly observed, calcification depth is generally estimated from $\mathrm{Mg} / \mathrm{Ca}$ or stable oxygen isotope data and hence more uncertain. Nevertheless, depth habitat and calcification depth are related as deeper dwelling species will also have a greater calcification depth.

Here we hypothesise that, similar to seasonality, the depth habitat and therefore calcification depth is related to temperature and that changes in temperature will lead to adjustments in depth habitat such that the environmental changes planktonic foraminifera experiences are minimised. The combined effect of seasonal and depth habitat tracking would be that temporal and spatial gradients in planktonic foraminiferal proxy records are reduced compared to the gradients in the mean annual value of the reconstructed parameter. For instance, in the case of temperature, it would lead to positive offsets from annual mean near-surface temperatures at times of cooling as planktonic foraminifera shift their seasonal and depth habitats to the warmer season and/or to shallower depths. The partitioning of this effect into seasonality and depth habitat likely varies by region, depending on the ratio of seasonal over vertical temperature variability in the upper water column (Fig. 1). This implies that for tropical species constraining the depth habitat will be more important than seasonality, whereas the opposite is true for species living in mid- and high latitudes.

Variability in seasonal and vertical habitat within individual species is well known and the dependency of foraminifera habitat on climate has been implicated before (Ganssen and Kroon, 2000; Mix, 1987; Mulitza et al., 1998; Jonkers and Kučera, 2015; Skinner and Elderfield, 2005). In addition, several modelling studies have investigated the potential dampening effect of seasonality (Fraile et al., 2009a, b; Kretschmer et al., 2016). However, surprisingly for an effect that may strongly affect proxy records, studies attempting to demonstrate the effect of habitat tracking, or the nonpassive recording by foraminifera (and how to deal with the problem) remain scarce. Moreover, while habitat tracking behaviour can be expected, a systematic quantification of the effect on planktonic foraminifera proxies based on observational evidence, as well as an assessment of the respective roles of seasonality and depth habitat, is lacking. Essentially, the existence of a habitat tracking effect on proxy signals in planktonic foraminifera has been treated either by attempting to derive a "correction factor" which was applied more or less uniformly (e.g. Barker et al., 2005) or by trying to detect the effect by multi-species analyses (Skinner and Elderfield, 2005). In both approaches, the most difficult aspect was to deal with the possibility of the effect of habitat tracking being variable.

Here we aim to bring the issue (back) to the attention of the community, stimulate discussion and suggest some ways forward. We use core top stable isotope data to first demon- 
G. ruber (white)

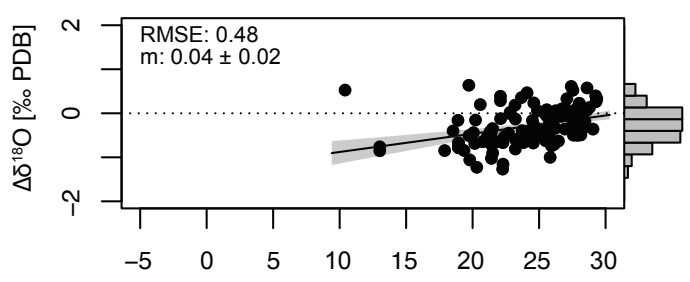

G. ruber (pink)

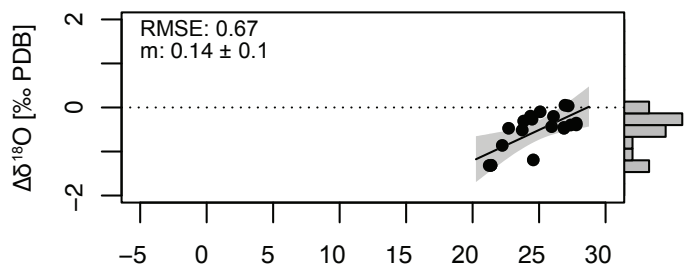

T. sacculifer

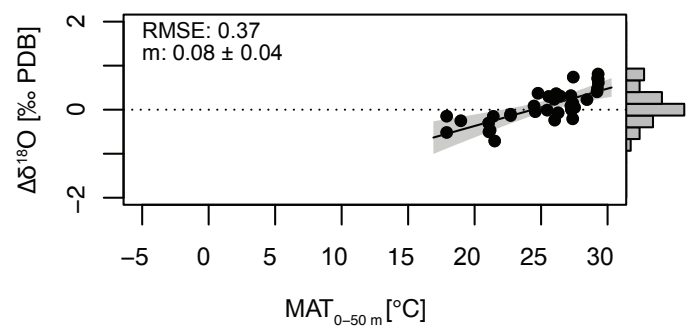

N. incompta

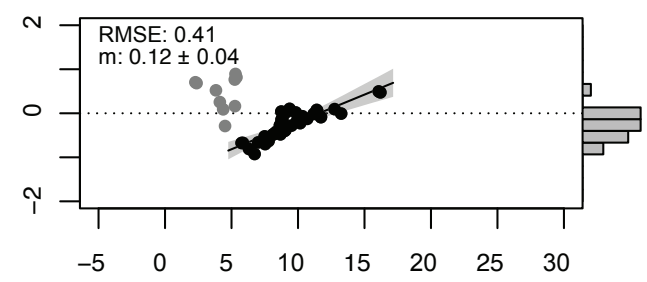

N. pachyderma

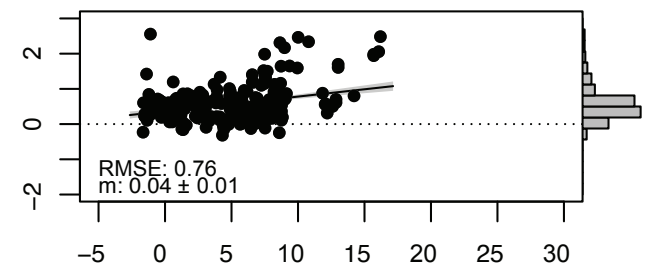

G. bulloides

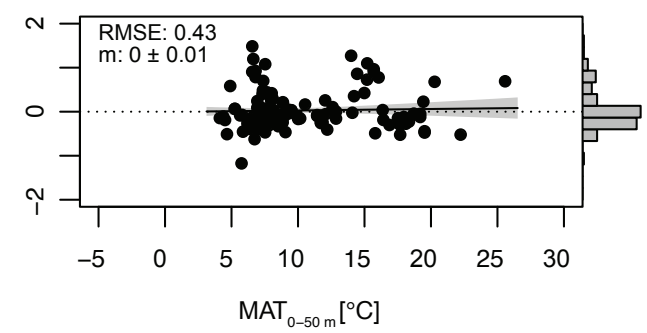

Figure 2. Temperature-dependent offsets between predicted annual mean near-surface and observed $\delta^{18} \mathrm{O}\left(\Delta \delta^{18} \mathrm{O}_{\text {annual.mean }}\right)$, suggesting habitat tracking. All species except $G$. bulloides show a trend in $\Delta \delta^{18} \mathrm{O}_{\text {annual.mean values with mean annual temperature in the upper } 50 \mathrm{~m}}$ $\left(\mathrm{MAT}_{0-50 \mathrm{~m}}\right)$ of the water column suggesting that planktonic foraminifera adjust their habitat to minimise temperature change in their

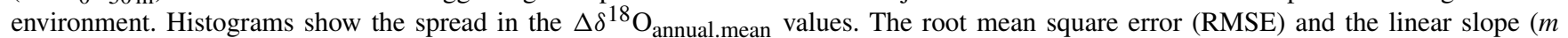
$\pm 90 \%$ confidence interval) of the $\Delta \delta^{18}$ O-temperature relationship are indicated in the upper left corner of each panel. The uncertainty envelopes depict the 5th to 95th percentile of the uncertainty on the MAT- $\Delta \delta^{18} \mathrm{O}_{\text {annual.mean }}$ relationships, which are indicated by the solid black line. The grey dots in the panel for $N$. incompta show the data that are excluded from further analyses as they most likely stem from right-coiling morphotypes of $N$. pachyderma.

strate that foraminifera proxies are indeed affected by habitat tracking. We then show that this effect can be parametrised and assess the relative importance of variable seasonality and depth habitat. Our findings have important implications for the interpretation of palaeoceanographic records and could help to bridge the gap between palaeoceanographic data and model simulations.

\section{Data and approach}

If shifts in depth and seasonal habitat would act to minimise the change in the ambient environment of the planktonic foraminifera, then the proxy signal preserved in their shells should show an offset from mean annual values that varies with temperature. To test this conjecture we compare core top stable oxygen isotope $\left(\delta^{18} \mathrm{O}\right)$ values from different species with seasonally and vertically resolved estimates of equilibrium $\delta^{18} \mathrm{O}$. We use quality-controlled data with strict age control (chronozone 1-4) from the MARGO core top dataset (Waelbroeck et al., 2005). This dataset contains data for six morphospecies of planktonic foraminifera: Trilobatus sacculifer $(n=38)$, Globigerinoides ruber (white $(n=131)$ and pink ( $n=20)$ varieties), Globigerina bulloides $(n=131)$, Neogloboquadrina incompta $(n=46)$ and Neogloboquadrina pachyderma $(n=253)$; the existence of different genotypes within these species was not taken into account. We exclude samples from the Mediterranean from our analysis because of difficulties in estimating seawater $\delta^{18} \mathrm{O}$ in this evaporative basin, and we removed T. sacculifer data from Pacific Ocean sites deeper than $3 \mathrm{~km}$ as these are thought to be affected by dissolution (Wu and Berger, 1989). We use the median standard deviation of replicate measurements in the dataset $(0.12 \%$ ) as an estimate of the observational uncertainty. This value reflects analytical uncertainty as well as uncertainty associated with different integration time of each 
sample and selective sampling due to low and variable numbers of shells used for analysis.

We compare the planktonic foraminifera $\delta^{18} \mathrm{O}\left(\delta^{18} \mathrm{O}_{\text {foram }}\right)$ to predicted $\delta^{18} \mathrm{O} \quad\left(\delta^{18} \mathrm{O}_{\text {eq }}\right)$ calculated using $\delta^{18} \mathrm{O}$ temperature equation by Kim and O'Neil (1997). Calibration uncertainty is estimated from measurements on planktonic foraminifera shells from sediment traps from a period of complete mixing of the upper water column (Jonkers et al., 2013). This value $(0.2 \%)$ is larger than the calibration error based on laboratory cultures (Bemis et al., 1998). Following the approach of LeGrande and Schmidt (2006) we estimate seawater $\delta^{18} \mathrm{O}$ using regionally defined salinity $-\delta^{18} \mathrm{O}_{\mathrm{sw}}$ relationships for the upper $200 \mathrm{~m}$ using the Global Seawater Oxygen-18 Database (Schmidt et al., 1999). Standard errors of prediction vary regionally and reach a maximum of $0.91 \%$ in the Arctic. Conversion from the Standard Mean Ocean Water to Pee Dee Belemnite scale was done by subtracting $0.27 \%$ (Hut, 1987). Temperature and salinity data were taken from the World Ocean Atlas 2001 (Boyer et al., 2002; Stephens et al., 2002) and area-weighted averages were obtained from the four $1^{\circ}$ grid cells surrounding each core top position.

We start with comparing the observed $\delta^{18} \mathrm{O}_{\text {foram }}$ to annual mean $\delta^{18} \mathrm{O}_{\mathrm{eq}}$ for the upper $50 \mathrm{~m}$ as this is the depth interval where these species are most likely to calcify. To estimate the uncertainty on the relationships between predicted and observed values we use a Monte Carlo approach. Assuming a normal distribution of the uncertainty, we perform regressions on 10000 representations of the data sampled within the combined range of uncertainty based on the square root of the sum of the squared errors mentioned above.

\section{Results and discussion}

\subsection{Habitat tracking in planktonic foraminifera}

The observed $\delta^{18} \mathrm{O}$ of all species show deviations from expected mean annual $\delta^{18} \mathrm{O}_{\text {eq }}$ by up to $3 \%$ (Fig. S1 in the Supplement). If our hypothesis of habitat tracking holds, the $\Delta \delta^{18} \mathrm{O}\left(\delta^{18} \mathrm{O}_{\text {foram }}-\delta^{18} \mathrm{O}_{\mathrm{eq}}\right)$ should show a positive relationship with temperature. Indeed, the $\Delta \delta^{18} \mathrm{O}_{\text {annual.mean values of }}$ the three warm-water species (G. ruber (white and pink) and $T$. sacculifer) show a significant positive relationship with mean annual temperature (MAT; Fig. 2). The slopes vary between 0.04 and $0.14 \% 0^{\circ} \mathrm{C}^{-1}$. In general, $\Delta \delta^{18} \mathrm{O}_{\text {annual.mean }}$ values are close to 0 at high mean annual temperatures and negative $\Delta \delta^{18} \mathrm{O}_{\text {annual.mean values, indicating calcification }}$ temperatures higher than annual mean, occur in colder waters. Among the cold-water species, $N$. incompta also displays a consistent positive relationship between temperatures and $\Delta \delta^{18} \mathrm{O}_{\text {annual.mean }}$ above $\sim 5^{\circ} \mathrm{C}$, whereas below this temperature the relationship has the opposite sign (Fig. 2). These observations at low temperature stem from samples in the Nordic Seas outside the direct path of the North Atlantic Drift. We suspect that these (partly) reflect right-
Table 1. Temperature-amplitude relationships for the modelled flux pattern of tropical species based on Jonkers and Kucera (2015).

\begin{tabular}{lrr}
\hline Species & intercept & slope \\
\hline G. ruber (pink) & 2.16 & -0.07 \\
G. ruber (white) & 0.99 & -0.02 \\
T. sacculifer & 0.85 & -0.02 \\
\hline
\end{tabular}

Table 2. Critical temperatures $\left({ }^{\circ} \mathrm{C}\right)$ that determine the phasing of the shell flux of cold-water species. Between these two temperatures the flux pattern is characterised by two peaks a year that shift as a function of temperature to earlier in the year in warmer water (Jonkers and Kučera, 2015).

\begin{tabular}{lrr}
\hline Species & T.crit.lo & T.crit.hi \\
\hline N. incompta & 9 & 15 \\
N. pachyderma & -5 & 7 \\
\hline
\end{tabular}

coiling variants of $N$. pachyderma (Bauch et al., 2003) and we have therefore excluded them from further analysis. $\Delta \delta^{18} \mathrm{O}_{\text {annual.mean }}$ values of $N$. pachyderma are generally positive and show an increased spread towards higher values in warmer waters (Fig. 2). G. bulloides is the only species that does not show any trend in $\Delta \delta^{18} \mathrm{O}_{\text {annual.mean; modal values }}$ are close to 0 , but the distribution is skewed towards positive offsets (Fig. 2). This species was therefore excluded from further analyses. In summary, five of the six species analysed display a pattern in their $\Delta \delta^{18} \mathrm{O}_{\text {annual.mean }}$ that is consistent with the hypothesis of habitat tracking acting to minimise the temperature change they experience. In all cases, the relationships are associated with substantial noise, but they are statistically significant and have similar slopes with the same sign. Such coincidence is unlikely to have arisen by chance and we conclude that the data demonstrate the existence of a habitat bias in foraminifera proxies, which varies as a function of temperature.

\subsection{Seasonality}

Next, using simple empirical models for seasonality we assess how much of the trend in $\Delta \delta^{18} \mathrm{O}_{\text {annual.mean }}$ could be due to changes in seasonality alone. To this end we calculate a flux-weighted $\delta^{18} \mathrm{O}_{\text {eq }}\left(\delta^{18} \mathrm{O}_{\text {season }}\right)$ for the upper $50 \mathrm{~m}$ of the water column using a simple seasonality model and compute $\Delta \delta^{18} \mathrm{O}_{\text {season. }}$. Based on previous work (Jonkers and Kučera, 2015) we describe the $\log _{10}$-transformed flux pattern as a sine wave of which we change the amplitude and phasing as a function of mean annual temperature. For warm-water species we fix the peak in the flux in September (March in the Southern Hemisphere), which is generally the warmest month, and linearly increase the amplitude with decreasing temperature with a species-specific slope derived from sediment trap data (Fig. 3; Table 1). While this model does not 

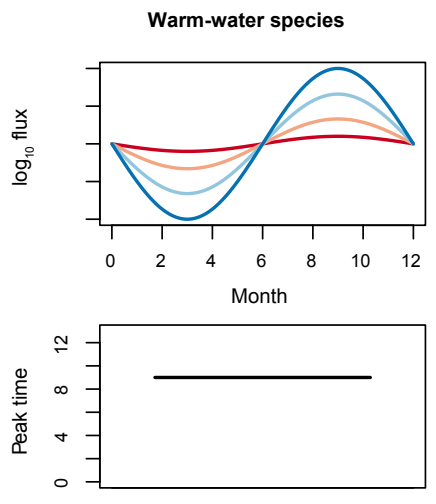

Temperature
Cold-water species
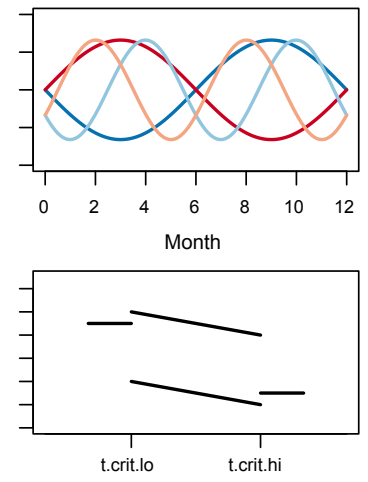

Temperature

Figure 3. Schematic representation of the seasonality model. Upper panels show the annual flux patterns; colours indicate temperature, where blue is cold and red is warm. Lower panels show the timing of the peak in the year. For a more detailed explanation of the model see Sect. 3.2 and Tables 1 and 2.

account for the random peak flux timing at high temperatures (Jonkers and Kučera, 2015), the seasonal amplitudes of the shell flux and of $\delta^{18} \mathrm{O}_{\mathrm{eq}}$ are very small in warm waters, and the model serves as a reasonable approximation of the seasonality pattern that characterises this species group. For cold-water species we fix the amplitude at the average value for this group (0.66) and vary the timing of the peak flux as a function of temperature (Fig. 3). Below a critical low temperature we set the peak timing to September and above a critical high temperature to March (reversed for the Southern Hemisphere); between these temperatures, the modelled flux pattern has two peaks a year that linearly shift towards earlier in the year in colder waters (Table 2). While simple, this model represents a realistic scenario that is derived from observations and can thus be applied to the studied species. We gauge the effect of the flux weighting by determining (i) the (change in the) spread of the $\Delta \delta^{18} \mathrm{O}$ values and (ii) the slope of the $\Delta \delta^{18} \mathrm{O}$-temperature relationship. The uncertainty of the $\Delta \delta^{18} \mathrm{O}_{\text {season }}$ values derived when using this model are initially estimated using the same Monte Carlo approach with the same error estimates as outlined above. We later test the sensitivity of the results to the parametrisation by repeating the analyses with formulations assuming stronger/weaker flux seasonality.

Accounting for seasonality using this model reduces the root mean square error (RMSE) in the $\Delta \delta^{18} \mathrm{O}$ values of $G$. ruber (pink) by $21 \%$ and the slope by $37 \%$ (Fig. 4). For G. ruber (white) the values are 12 and $77 \%$ respectively (Fig. 4). Due to large positive $\Delta \delta^{18} \mathrm{O}$ values for T. sacculifer at high temperatures, flux weighting has a negligible effect on the spread in the values (1\%), but it reduces the slope by $22 \%$ (Fig. 4). The values for N. incompta are 47 and $57 \%$ and for N. pachyderma 16 and $51 \%$ (Fig. 4). For none of the species

G. ruber (white)

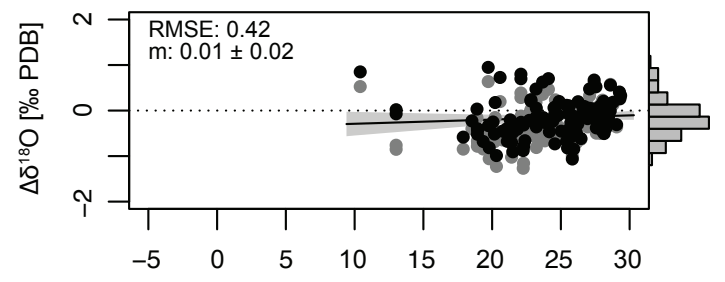

G. ruber (pink)

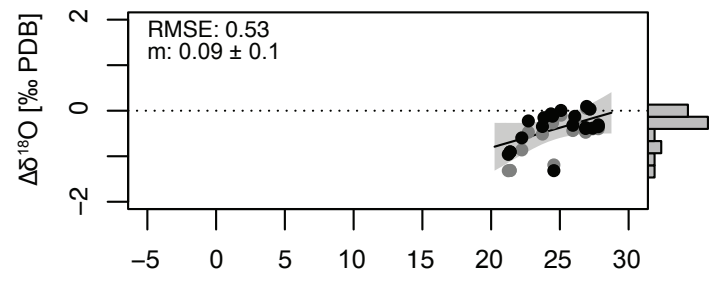

T. sacculifer
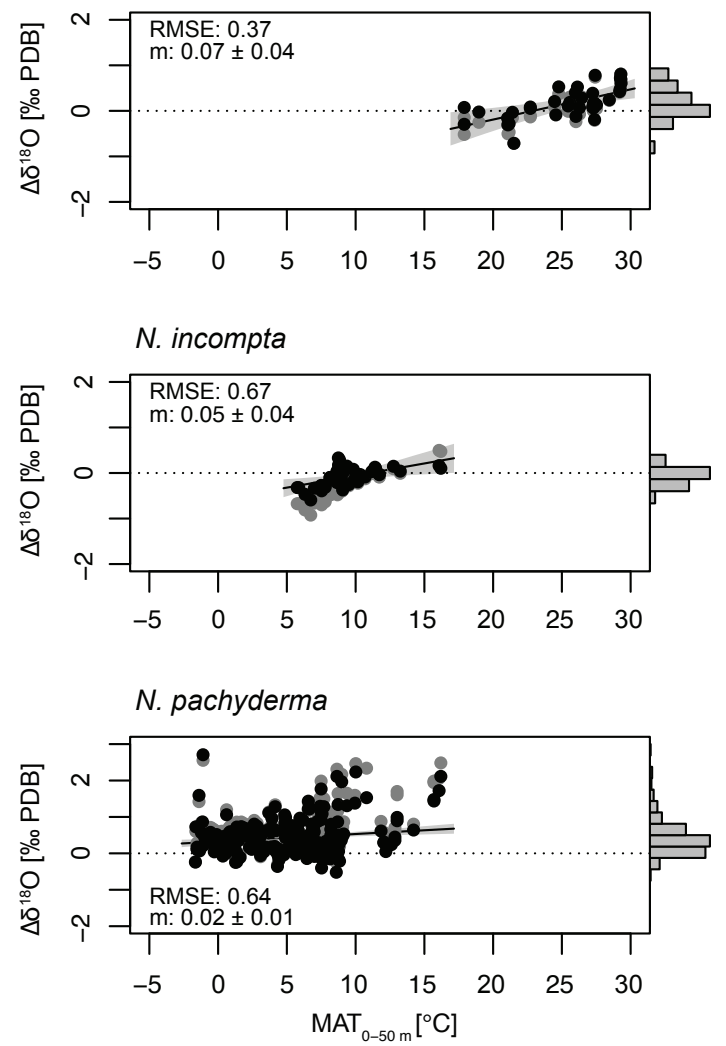

Figure 4. Offset between flux-weighted $\delta^{18} \mathrm{O}$ predicted using the seasonality model depicted in Fig. 3 and observed $\delta^{18} \mathrm{O}$ ( $\Delta \delta^{18} \mathrm{O}_{\text {season }}$. Grey symbols represent $\Delta \delta^{18} \mathrm{O}_{\text {annual.mean }}$ (Fig. 2). Note the general reduction in the spread of the data (RMSE) and

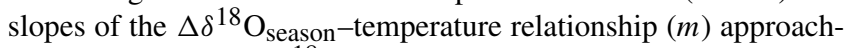
ing 0 , compared to $\Delta \delta^{18} \mathrm{O}_{\text {annual.mean }}$ (Fig. 2), suggesting that seasonal habitat tracking partly explains the trends shown in Fig. 2. Error envelopes as in Fig. 2. 
does this adjustment for seasonality lead to an increase in the spread of the $\Delta \delta^{18} \mathrm{O}$ values; on the contrary, in most cases the predicted $\delta^{18} \mathrm{O}_{\mathrm{eq}}$ are closer to the $\delta^{18} \mathrm{O}_{\text {foram }}$. This indicates that even by using a simple empirical model for seasonality, predictions of the fossil signal can be improved.

\subsection{Calcification depth}

In none of the species investigated here does the adjustment for seasonality completely remove the relationship between $\Delta \delta^{18} \mathrm{O}_{\text {season }}$ and temperature, although in the case of $G$. ruber seasonality adjustment could remove the $\Delta \delta^{18} \mathrm{O}-\mathrm{MAT}$ slope when the full range of uncertainties is considered (confidence intervals on slopes as shown in Fig. 3 contain zero). Therefore, one may assume that at least a part of the relationship could reflect an adjustment of calcification depth. To investigate whether the trends in the $\Delta \delta^{18} \mathrm{O}_{\text {season }}$ reflect an increase of calcification depth towards the tropics, we determine the depth at which $\Delta \delta^{18} \mathrm{O}_{\text {season }}$ is smallest and assess whether there is a relationship between this apparent calcification depth and mean annual temperature. This reveals that, of the warm-water species, G. ruber (pink) shows the shallowest (apparent) calcification depth, followed by G. ruber (white) and T. sacculifer (Fig. 5). This rules out the possibility that the relationships between $\Delta \delta^{18} \mathrm{O}$ and temperature (Figs. 2 and 4) reflect calcification at a constant but greater depth than in the near-surface layer. Rather, this correlation is consistent with the hypothesis that planktonic foraminifera (passively) track an optimum vertical habitat. N. incompta has variable calcification depths that show a steep slope with

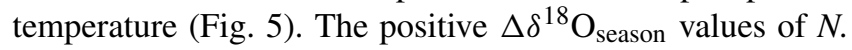
pachyderma indicate a calcification depth consistently below $50 \mathrm{~m}$ (Fig. 5).

Next we use the linear relationships between apparent calcification depth and temperature (Fig. 5) to improve the prediction of the fossil signal. We thus adjust the $\delta^{18} \mathrm{O}_{\text {season }}$ to a depth-specific signal, using the depth-temperature relationship identified earlier (Fig. 5) to calculate $\Delta \delta^{18} \mathrm{O}_{\text {season.depth }}$. In $G$. ruber (pink) this leads to a further $50 \%$ reduction in the RMSE and a $\Delta \delta^{18} \mathrm{O}_{\text {season.depth-temperature slope that is }}$ close to 0 (Fig. 6). In G. ruber (white) the reduction in the spread in the data is more modest $(12 \%)$ and so is the reduction in slope (Fig. 6). Similarly, for T. sacculifer also only modest additional reductions are achieved: 8 and $11 \%$ for RMSE and slope respectively (Fig. 6). Among the cold-water species $N$. incompta shows the clearest relationship between $\Delta \delta^{18} \mathrm{O}_{\text {season.depth }}$ and temperature and adjustment for calcification depth yields a reduction of the RMSE of 8 and of the slope of $46 \%$, of which the uncertainty range now encompasses 0 (Fig. 6). In N. pachyderma no further reduction in the slope is achieved but the RMSE decreases by $22 \%$.
G. ruber (white)

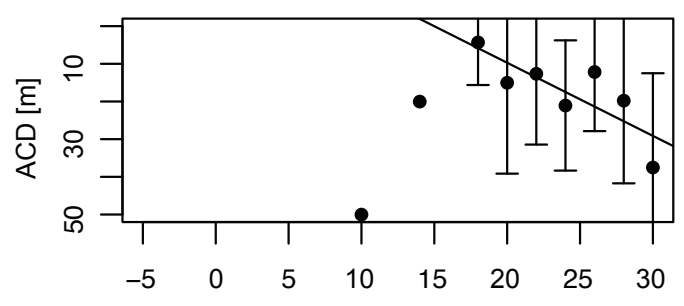

G. ruber (pink)

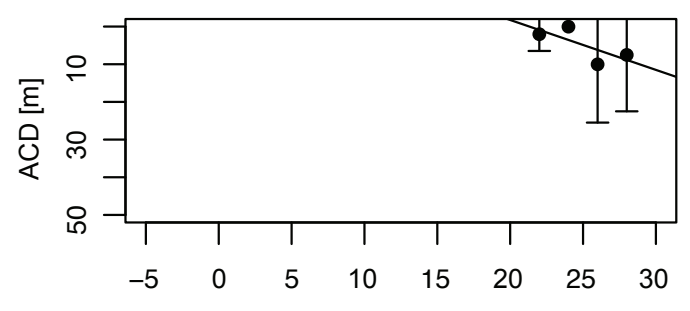

T. sacculifer

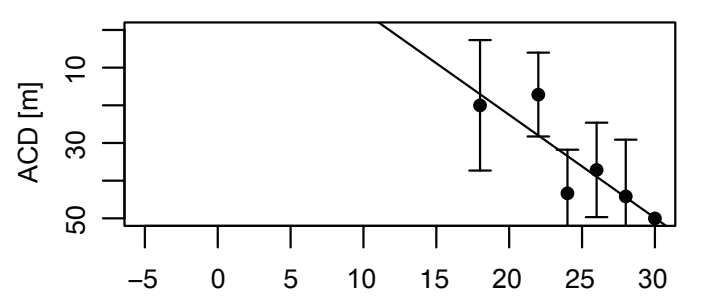

N. incompta

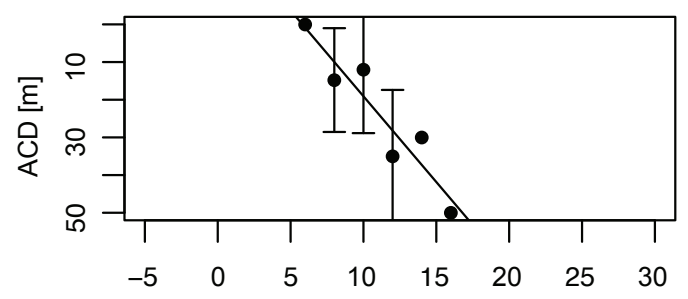

N. pachyderma

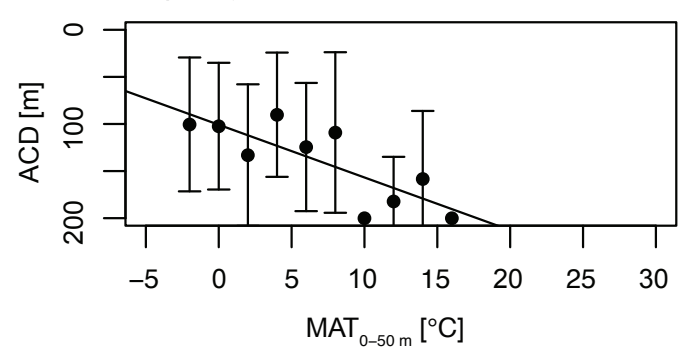

Figure 5. Relationship between apparent calcification depth (ACD) and temperature. Data are summarised in $2^{\circ} \mathrm{C}$ bins and error bars represent standard deviations within each bin. The data points at the cold temperature end of G. ruber (white) are excluded since these are more likely to reflect outliers or advected specimens. 


\subsection{Seasonality vs. depth habitat}

G. ruber (white)

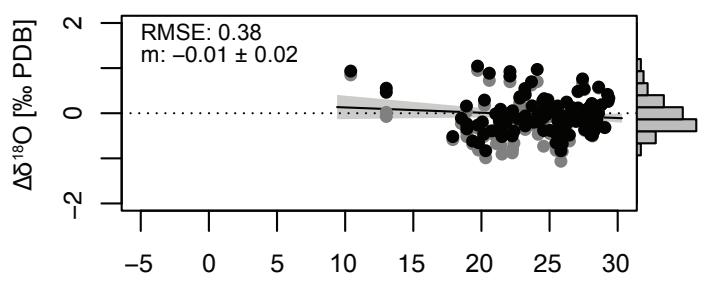

G. ruber (pink)

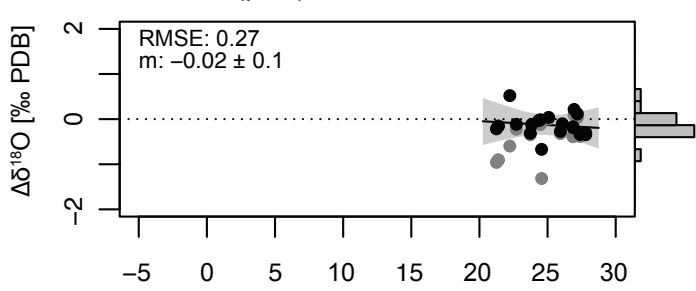

T. sacculifer
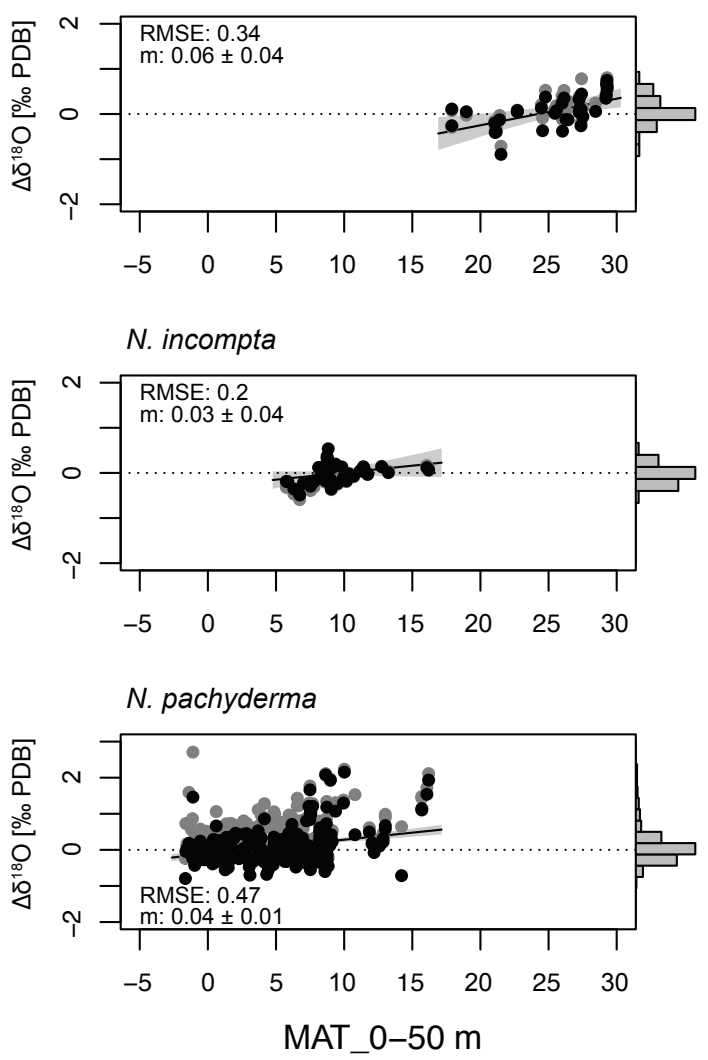

Figure 6. Offset between seasonality- and depth-adjusted $\delta^{18} \mathrm{O}_{\mathrm{eq}}$ and $\delta^{18} \mathrm{O}_{\text {foram. }}$. In most cases both the RMSEs and the $\Delta \delta^{18} \mathrm{O}-$ temperature slopes are reduced, indicating further improvement in the prediction of foraminifera $\delta^{18} \mathrm{O}$ and suggesting that the simple empirical parametrisation of habitat variability can be used to correct for habitat tracking. Grey symbols represent $\Delta \delta^{18} \mathrm{O}_{\text {season; }}$; error envelopes as in Fig. 2.
Our analysis allows assessing the relative contribution of seasonality and calcification depth change in explaining the variable $\Delta \delta^{18} \mathrm{O}_{\text {annual.mean }}$ for species where temperature seems important for determining their habitat. In general, the improvement of the prediction of the $\delta^{18} \mathrm{O}_{\text {foram }}$ is larger for the slope of the $\Delta \delta^{18} \mathrm{O}$-temperature relationship than for the spread in the $\Delta \delta^{18} \mathrm{O}$ values (Fig. 7). This may point to some degree of inherent noise in the observations (e.g. related to different size fractions used for the measurements; Friedrich et al., 2012), or it could also be due to uncertainty in the $\delta^{18} \mathrm{O}_{\mathrm{eq}}$ values, which are based on climatology and salinity-based estimates of $\delta^{18} \mathrm{O}_{\mathrm{sw}}$. Moreover, the noise may also reflect the simplicity of the seasonality model we have used. Nevertheless, G. ruber (pink) and N. incompta show coherent behaviour with respect to both parameters (Fig. 7). For $N$. incompta seasonality explains most of the trend in $\Delta \delta^{18} \mathrm{O}_{\text {annual.mean }}$, whereas for $G$. ruber (pink) depth habitat appears more important. This is consistent with their distribution: $N$. incompta predominantly inhabits high and mid-latitudes where seasonal temperature change is larger than vertical temperature gradients and G. ruber (pink) is restricted to the tropics where the opposite situation prevails (Fig. 1). This pattern provides support for our approach and suggests that both seasonality and depth habitat variability are important for interpretation of the proxy signal preserved in the sediment. The picture is less clear for G. ruber (white) and T. sacculifer. For the latter species the improvement in the prediction of their $\delta^{18} \mathrm{O}$ is generally smaller, which may be due to a remnant dissolution signal at the hightemperature end of the species distribution in the Pacific. For G. ruber (white), the signal-to-noise ratio in the data appears lower than in the other species, which may reflect a disproportionate effect of secondary variables, such as changing proportionality and inconsistent recognition of the ecologically distinct morphotypes (Steinke et al., 2005) that are now assigned to different taxa (Aurahs et al., 2011).

An important caveat in the attribution of the improvement in the prediction of the fossil proxy signal to either seasonality or calcification depth is the form and parametrisation of the seasonality model used. We therefore explored the sensitivity of our model to changes in the slope and intercept of the flux amplitude-temperature relationship (Fig. S2). This suggests that the formulation of seasonality in our model is conservative: weaker seasonality parametrisation leaves much larger residuals and a slope that cannot be accounted for by depth habitat adjustment. However, we note that in the case of G. ruber pink there exists a parametrisation of flux seasonality that leads to a greater improvement in the prediction of $\delta^{18} \mathrm{O}_{\text {foram }}$ and implies a constant habitat depth adjustment. However, we feel that the parametrisation based on actual data (Jonkers and Kučera, 2015), even if conservative, is the most realistic. It is also important to realise that the sine wave as a template for the seasonal flux pattern is only an approx- 


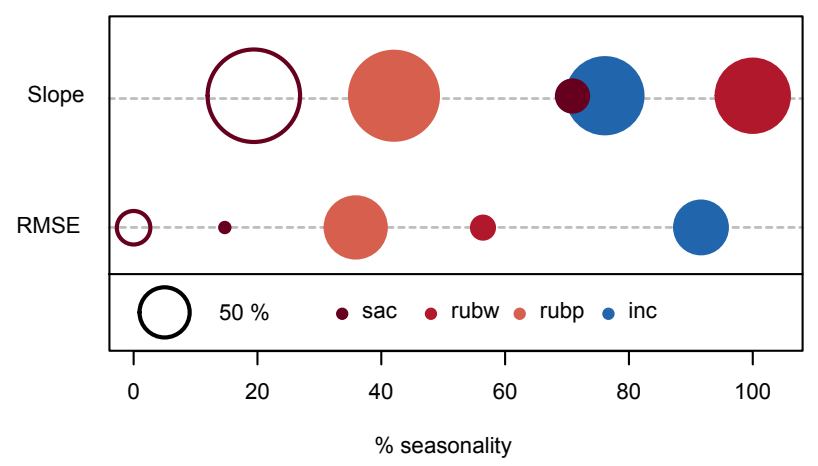

Figure 7. Partitioning of the improvement in the prediction of the fossil $\delta^{18} \mathrm{O}$ signal into seasonality and depth habitat for both RMSE of $\Delta \delta^{18} \mathrm{O}$ and the slope between $\Delta \delta^{18} \mathrm{O}$ and $\mathrm{MAT}_{0-50 \mathrm{~m}}$. Colours denote species and the size of each dot is proportional to the total improvement achieved. The open circles illustrate the partitioning for T. sacculifer using the palaeotemperature equation of Mulitza et al. (2003).

imation. Seasonal flux pulses are often narrower and more focussed, leading to flux weighting to a shorter period within the year. This too implies that the model used here is a conservative estimate of the importance of seasonality.

Finally, implicit in our approach is the assumption that planktonic foraminifera form their skeleton accordance with inorganic calcite precipitation and that their $\delta^{18} \mathrm{O}$ can be described using the equation by Kim and O'Neil (1997). While this appears to be the case for some species (Jonkers et al., 2010, 2013; Loncaric et al., 2006), there are also indications that, in particular for tropical species, different equations are more appropriate (Mulitza et al., 2003; Spero et al., 2003). Species-specific palaeotemperature equations proposed by the latter authors have a non-quadratic form with almost identical slopes to the Kim and O'Neil (1997) equation. However, they are offset by $0.3-0.6 \%$, with the offset slightly increasing with temperature. For instance, the Mulitza et al. (2003) equation for T. sacculifer would indicate more positive $\Delta \delta^{18} \mathrm{O}_{\text {annual.mean values and slightly steeper }}$ $\Delta \delta^{18} \mathrm{O}$-temperature relationships (Fig. 8). This suggests a generally greater calcification depth and would change the attribution of depth habitat and seasonality influence, rendering depth habitat more important (Fig. 7). However, it would not affect our main conclusion that the proxy signal of planktonic foraminifera is affected by habitat tracking.

\subsection{Additional factors affecting foraminifera proxies}

Five out of six species analysed here show a temperature dependency of the offset between $\delta^{18} \mathrm{O}$ of the foraminiferal shells and the annual mean $\delta^{18} \mathrm{O}$ of the upper water column (Fig. 2). In addition, these species show a positive relation between apparent calcification depth and temperature (Fig. 5). Together, these observations provide a strong indi-
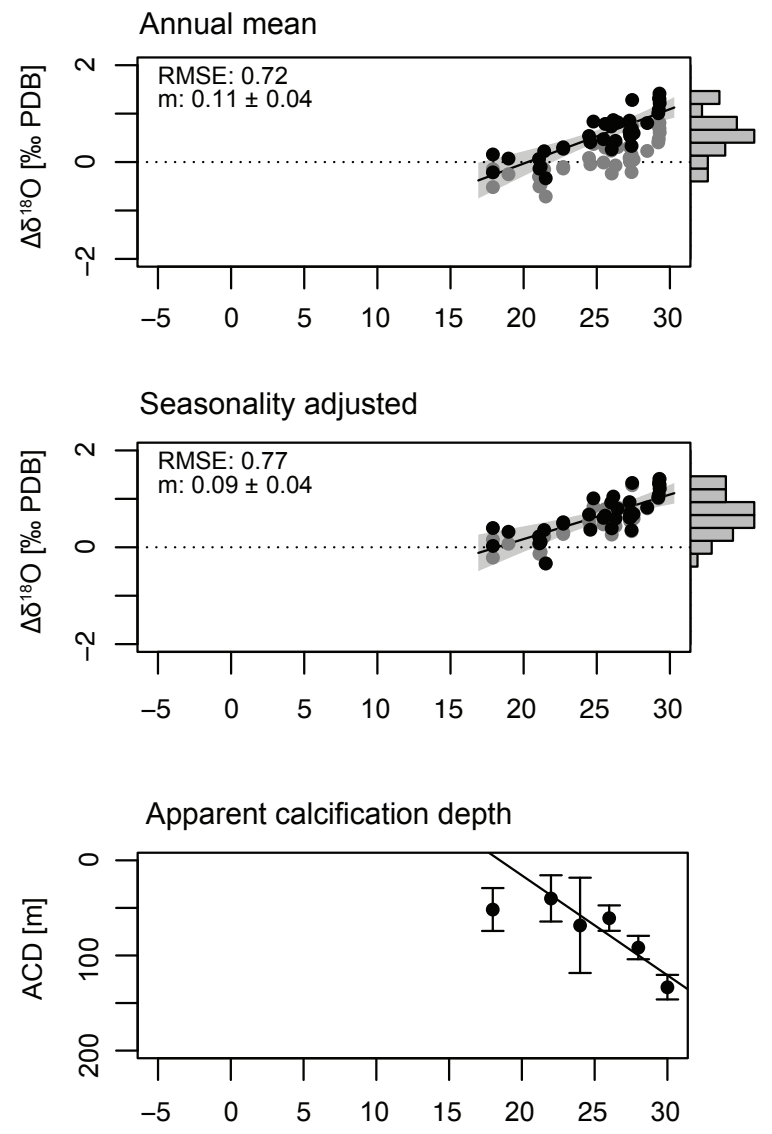

Seasonality and depth adjusted

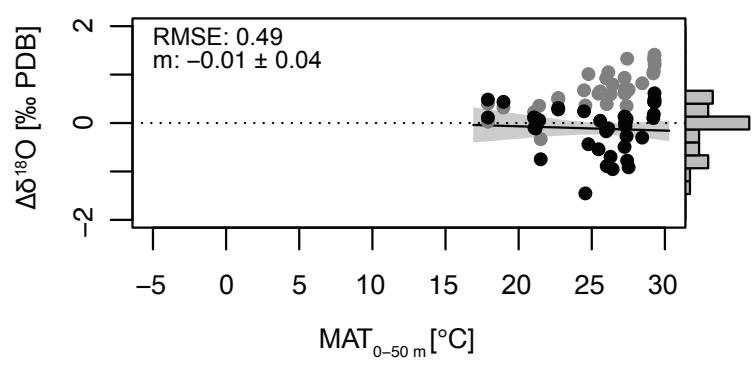

Figure 8. Assessing the effect of the use of a different palaeotemperature equation. The panels show the same information as Figs. 2, 4, 5 and 6 respectively but for $T$. sacculifer and using the equation of Mulitza et al. (2003). Note that the basic patterns indicative of habitat tracking remain but that the general calcification depth appears greater, also at lower temperatures.

cation that temperature, either directly or by acting on other variables, causes changes in the habitat of foraminifera. Such an important role for temperature in predicting the vertical and seasonal habitat is not unexpected given that temperature appears to be strongly correlated to the spatial distribution of species (Morey et al., 2005; Bé and Hutson, 1977), their flux (Zaric et al., 2005) and seasonality (Jonkers and Kučera, 
2015) and appears important for test growth (Lombard et al., 2009).

Several studies have shown that formation of secondary calcite layers (e.g. gametogenic calcite or a crust) at the end of the life of a specimen. Such encrustation could in principle affect our interpretation, since encrustation presumably occurs deep in the water column and could be responsible for higher $\delta^{18} \mathrm{O}$ of sedimentary foraminifera compared to those collected in the upper water column (Duplessy et al., 1981; Bé, 1980). To the best of our knowledge there is no evidence that such secondary calcite is formed with a different isotopic (dis)equilibrium than the lamellar calcite. We therefore assume that our inferences are not affected by differences in calcification during ontogeny. Nevertheless, the addition of such a crust in deeper (colder) waters could in principle lead to the observed increase in apparent calcification depth with temperature because of steeper vertical temperature gradients in the tropics. However, foraminifera shell mass increases exponentially during growth and the last chambers that make up most of the test mass are formed in the last few days of their life, presumably close to the time of the secondary calcite formation (Bé, 1980). The compositional contrast between the bulk of the lamellar calcite and the crust calcite is thus likely to be smaller than estimated from the comparison of surface tows and sediment (cf. Jonkers et al., 2016). Consequently, the apparent calcification depth we infer here likely incorporates this effect and the increase in apparent calcification depth that we observe most likely reflects habitat adjustment.

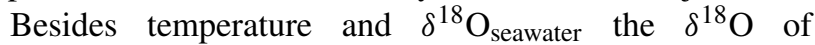
foraminiferal calcite is to a lesser degree also influenced by the $\mathrm{CO}_{3}^{2-}$ concentration in seawater (Spero et al., 1997). Because of the generally positive correlation between temperature and $\left[\mathrm{CO}_{3}^{2-}\right]$ in seawater, the trends we observe in $\Delta \delta^{18} \mathrm{O}_{\text {annual.mean }}$ (Fig. 2) could be dampened by a $\mathrm{CO}_{3}^{2-}$ influence. However, the $\mathrm{CO}_{3}^{2-}$ effect is only modest $\left(0.002 \% \mu^{2} \mathrm{~mol}^{-1} \mathrm{~kg}^{-1}\right)$ and to fully account for the on average $1 \%$ o difference we observe over the temperature range in our dataset, unrealistically large gradients in $\left[\mathrm{CO}_{3}^{2-}\right]$ would be required. The observed $\Delta \delta^{18} \mathrm{O}-\mathrm{MAT}$ trends thus most likely dominantly reflect real changes in the habitat of planktonic foraminifera.

While the majority of the species investigated here show clear indications of temperature-dependent depth and seasonal habitat variability, the picture for N. pachyderma is less clear. In the species most of the trend in $\Delta \delta^{18} \mathrm{O}_{\text {annual.mean }}$ values appears driven by an increased spread in $\Delta \delta^{18} \mathrm{O}$ at higher temperatures (Fig. 2). Some of these values are unrealistically large and stem from observations in the northern North Atlantic south of $50^{\circ} \mathrm{N}$ and are thus outside the general distribution range of the species. This suggests that these observations may reflect expatriated specimens that calcified in colder regions or may point to inaccuracies in the chronological control and reflect (partly) shells of glacial age. Alternatively, these samples could be affected by admixture of sinis- trally coiled $N$. incompta (Darling et al., 2006). It is puzzling though that the effect of seasonality is not larger since the species shows a clear latitudinal shift in the timing of the peak flux (Jonkers et al., 2010, 2013; Jensen, 1998; Wolfteich, 1994; Kohfeld et al., 1996). However, the species is also known to inhabit a broad, but generally deeper, zone of the upper water column (Carstens et al., 1997; Pados and Spielhagen, 2014) where seasonal temperature is smaller than in the near-surface layer, possibly rendering a seasonality effect difficult to detect.

Even though the absence of a $\Delta \delta^{18} \mathrm{O}_{\text {annual.mean- }}$ temperature trend in $G$. bulloides may suggest that this species holds the best promise of providing reconstructions of mean annual near-surface conditions (Fig. 2),

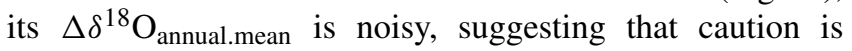
required to interpret the species proxy signal. Similar to $N$. pachyderma this species also shows clear latitudinal changes in seasonality (Jonkers and Kučera, 2015; Tolderlund and Bé, 1971). However, G. bulloides is characterised by considerable cryptic diversity (Darling and Wade, 2008). Possible genotypic ecological differences could therefore obscure ecological patterns at the morphospecies level. Alternatively, given that $G$. bulloides is an opportunistic species, its depth and seasonal habitat variability may be driven by other parameters than temperature. Indeed, previous studies have shown that the distribution of this species is driven by food availability (Schiebel et al., 1997; Jonkers and Kučera, 2015). Whether or not the species shows habitat tracking and how this would affect its fossil record remains unclear, but we caution that the result of our study cannot be taken to indicate that proxy records from this species record the actual magnitude of environmental change.

\subsection{Implications and outlook}

Habitat tracking behaviour of planktonic foraminifera has important implications for palaeoceanographic reconstructions. For example, it implies that the temperature niche of planktonic foraminifera inferred from their abundance in the sediment (e.g. Kucera, 2007) may be overestimated since their occurrence is not related to mean annual sea surface temperature but rather to whether their temperature niche is realised at any depth or season. It should thus be possible to define planktonic foraminifera temperature ranges (sensitivity) more precisely, which may help to improve transfer functions.

Another consequence of habitat tracking is that spatial and temporal differences reflected in the sedimentary foraminifera represent an underestimation of the actual gradients in the mean conditions, because temperature change forces the foraminifera to live in a seasonal or vertical "window" where conditions are closest to optimal (cf. Jonkers and Kučera, 2015). We observe considerable variability in the slope of the $\Delta \delta^{18} \mathrm{O}_{\text {annual.mean-temperature relationships, }}$ but the average for the four species that show the clearest 


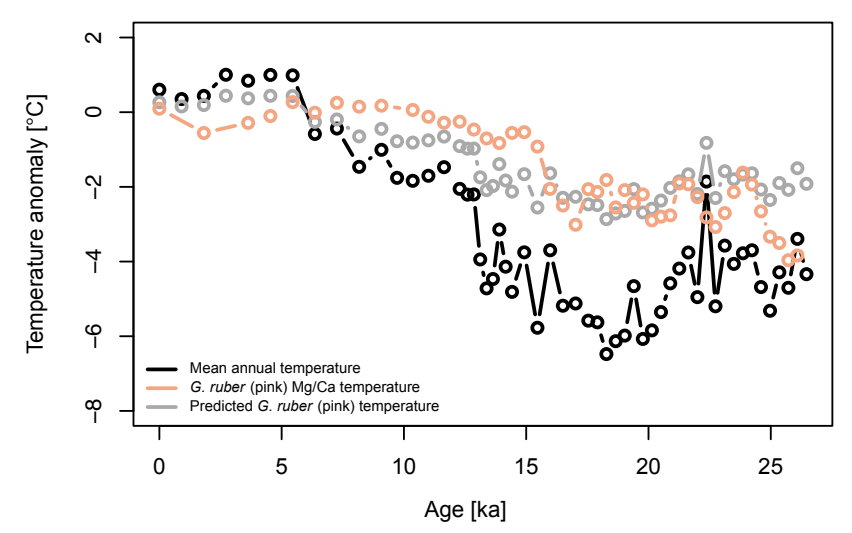

Figure 9. Effect of habitat tracking: reduced magnitude of deglacial temperature change estimated from $\mathrm{Mg} / \mathrm{Ca}$ of G. ruber (pink; Elderfield and Ganssen, 2000) compared to faunal assemblage based seasonal temperature estimates (Chapman et al., 1996) in the subtropical North Atlantic. The predicted G. ruber (pink) temperature, which is similar to the $\mathrm{Mg} / \mathrm{Ca}$ temperature, is based on the relationship identified in Fig. 2 and the assemblage-derived temperatures. Values are anomalies with respect to the $0-10000$ years BP average.

signal (G. ruber (pink and white), T. sacculifer and N. incompta) is $0.1 \% \circ,{ }^{\circ} \mathrm{C}^{-1}$ (Fig. 2). This is equivalent to a $40 \%$ $\left(0.4{ }^{\circ} \mathrm{C}^{\circ} \mathrm{C}^{-1}\right)$ underestimation of reconstructed temperature change.

It is important to note that habitat tracking would affect not only stable isotope records and $\mathrm{Mg} / \mathrm{Ca}$-based temperature estimates but also any geochemical proxy measured on planktonic foraminifera. However, the size of the effect will depend on the magnitude of the seasonal and vertical gradients in the parameters that are inferred. Recognising habitat tracking and deconvolving the effects of seasonality and calcification depth in data from the fossil record is, however, not straightforward. For instance, minor changes in mean temperature may be accommodated by changes in the habitat of foraminifera and remain invisible. Nevertheless, the existence of habitat-tracking-related underestimation can be observed through comparison of time series of different temperature proxies. Previous studies have shown that Holocene temperature trends and temperature variability inferred from foraminiferal $\mathrm{Mg} / \mathrm{Ca}$ ratios are generally of lower magnitude than those derived from alkenone unsaturation indices (Gill et al., 2016; Leduc et al., 2010). While it is not a priori clear that the alkenone signal is unaffected by seasonal habitat variability of coccolithophores (RosellMelé and Prahl, 2013), this comparatively low variability inferred from planktonic foraminifera proxies provides support that habitat tracking minimises the amplitude of the recorded environmental change. Comparison of $\mathrm{Mg} / \mathrm{Ca}-$ derived and transfer-function-based temperature evolution across the deglaciation provides further indications that habitat tracking dampens the foraminifera proxy signal (Fig. 9).
While both proxies indicate a clear warming step during the deglaciation, the amplitude of the $\mathrm{Mg} / \mathrm{Ca}$-based estimate is significantly lower. In addition, the single-species $\mathrm{Mg} / \mathrm{Ca}-$ temperature estimate lacks the smaller cooling and warming trends seen in the transfer-function-based estimate during the glacial and Holocene respectively. Using the linear $\Delta \delta^{18} \mathrm{O}_{\text {annual.mean-temperature relationship (Fig. 2) we }}$ also predicted the $G$. ruber (pink) temperature signal assuming that the assemblage-based temperatures represent an accurate estimate of mean annual temperature and using a $\delta^{18} \mathrm{O}$-temperature sensitivity of $0.25 \%{ }^{\circ} \mathrm{C}^{-1}$ (Fig. 9). The high degree of agreement between the predicted and observed temperature evolution provides quantitative support for the idea that habitat tracking reduces the amplitude of the foraminifera proxy signal.

Accounting for the dampening effect due to habitat tracking would increase the magnitude of reconstructed climate change as well as estimates of climate variability on longer timescales. This could have profound implications for inferred climate dynamics; it may mean, for instance, that estimates of climate sensitivity (e.g. Snyder, 2016) may be too low (or at least that the uncertainty of the estimate can be reduced). In addition, model-data comparison indicates that climate models systematically underestimate temperature variability (Laepple and Huybers, 2014), which has implications for both attribution of ongoing climate change as well as for climate predictions. Since habitat tracking dampens variability in the foraminifera proxy record, the mismatch between modelled and reconstructed climate variability may be even larger.

Several approaches are possible to account for underestimation due to habitat tracking. Ideally, several approaches should be combined - and their consistency checked - to arrive at the most accurate reconstruction of past climate associated with the most meaningful estimate of the uncertainty. The approaches range from very simple and widely applicable to more sophisticated and harder to apply as they require more input parameters to model the foraminifera habitat.

The simplest would be to use the observed slopes of $\Delta \delta^{18} \mathrm{O}_{\text {annual.mean-MAT relationships (Fig. 2) to correct the }}$ dampening effect. This approach can be applied to any single-species planktonic foraminifera proxy time series without the need for additional data. However, it is a "black box" method that relies on parametrisation derived from core top observations, and it may not work under oceanographic conditions different from today. Nevertheless, the similarity between the temperature signal of $G$. ruber (pink) and the prediction based on the annual mean reconstructed temperature in the example in Fig. 9 suggest that this method provides a useful first-order approximation of the actual amplitude of temperature change.

Alternatively, multi-proxy and/or multi-species approaches can be applied to observe offsets between species and proxies and use this information to directly constrain the variable habitat bias (e.g. Skinner and Elderfield, 2005). 

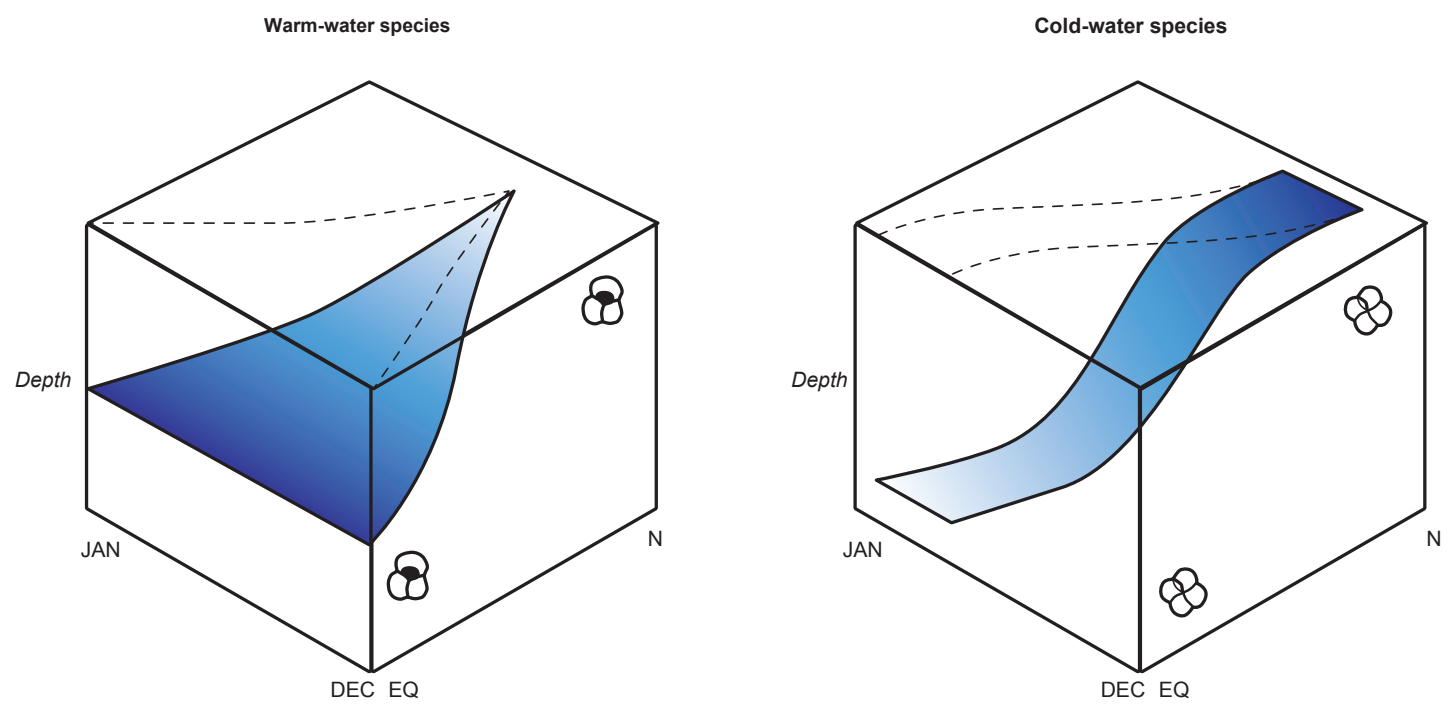

Figure 10. Conceptual model of calcification habitat change for warm- and cold-water species. The coloured plane indicates the average calcification season and depth as a function of latitude. Dashed lines on top highlight the change in the seasonality.

However, to use this method, better constraints on the calibration of the individual proxies are needed. This is because most proxies are affected by multiple parameters, rendering a multi-proxy (or multi-species) dataset underdetermined. In this context, a potential shortcut could be to build on the central premise of assemblage transfer functions, i.e. that a species becomes rarer further away from its optimum habitat, and investigate whether relative abundance can be used to correct for habitat tracking. This approach would integrate all the environmental forcings contained in fossil assemblages and hence provide estimates of habitat tracking independent of the reconstructed parameter.

Finally, habitat tracking could be accounted for using direct proxy modelling. This approach requires a priori knowledge of the habitat predictor(s) and its change through time, rendering it particularly suitable for comparison of climate model simulations with proxy data. However, if the predictor can be reconstructed independently, the approach could, in theory, also be used in purely proxy-based studies. An early example of this approach is the conceptual model of Mix (1987). At the other end of the model complexity spectrum are ecological models that take multiple factors affecting foraminifera habitat into account (Lombard et al., 2011; Fraile et al., 2008). In this study, we have demonstrated the power of an intermediate empirical approach to parametrise planktonic foraminifera habitat variability that could be used to improve the accuracy of planktonic foraminifera proxy records.

\section{Conclusions}

Through comparison of observed and predicted $\delta^{18} \mathrm{O}$ data of six common planktonic foraminifera we have demonstrated that the average geochemical signal preserved in a population of fossil shells shows a temperature-dependent offset from mean annual sea surface conditions. This most likely reflects shifts in the seasonal and depth habitat in response to temperature, or temperature-related environmental, changes (Fig. 9). As a consequence of this behaviour, the fossil record of these species, and likely also of others, does not reflect the full range of climate variability. Our analysis indicates that spatial and temporal gradients in temperature may be underestimated by as much as $40 \%$, highlighting the need to account for climate-dependent habitat variability in the interpretation of palaeoceanographic records based on planktonic foraminifera. Using a simple empirical model we attempted to assess the relative influence of seasonality and depth habitat variability. We observe species-specific partitioning of depth habitat versus seasonality that appears consistent with oceanographic conditions within their areal distribution. In the warm-water species G. ruber (pink) we find that habitat tracking is primarily due to adjustments in the calcification depth. This is in agreement with the larger vertical than seasonal temperature gradients in the tropics. The offsets from annual mean surface conditions in $N$. incompta, on the other hand, appear dominantly driven by changes in the seasonality, consistent with the dominance of seasonal over vertical temperature variability in the regions where it occurs. This demonstration of predictable habitat tracking will help to improve the accuracy of palaeoceanographic reconstructions and aid model-data comparison. Our analysis emphasises that an observed change in planktonic foraminifera 
proxies reflects a change in the climate state as well as a change in the species habitat.

Data availability. The data used in this study are all in the public domain: foraminifera data are available at https://doi.pangaea. de/10.1594/PANGAEA.227321; WOA01 data at https://www.nodc. noaa.gov/OC5/WOA01/woa01dat.html and the global seawater oxygen-18 database at https://data.giss.nasa.gov/o18data/. A data sheet is also provided in the Supplement. R ( $\mathrm{R}$ core team, 2016) code is available upon request from $\mathrm{L}$. Jonkers.

\section{The Supplement related to this article is available online at https://doi.org/10.5194/cp-13-573-2017-supplement.}

Competing interests. The authors declare that they have no conflict of interest.

Acknowledgements. We thank Stefan Mulitza and Thomas Laepple for valuable discussions and constructive comments from two reviewers and the editor Luke Skinner, which helped to improve this manuscript. L. Jonkers was supported by the German climate modelling initiative PalMod, funded by the Federal Ministry of Education and Research (BMBF).

The article processing charges for this open-access publication were covered by the University of Bremen.

Edited by: L. Skinner

Reviewed by: two anonymous referees

\section{References}

Aurahs, R., Treis, Y., Darling, K., and Kucera, M.: A revised taxonomic and phylogenetic concept for the planktonic foraminifer species Globigerinoides ruber based on molecular and morphometric evidence, Mar. Micropaleontol., 79, 1-14, https://doi.org/10.1016/j.marmicro.2010.12.001, 2011.

Barker, S., Cacho, I., Benway, H., and Tachikawa, K.: Planktonic foraminiferal $\mathrm{Mg} / \mathrm{Ca}$ as a proxy for past oceanic temperatures: a methodological overview and data compilation for the Last Glacial Maximum, Quaternary Sci. Rev., 24, 821-834, 2005.

Bauch, D., Darling, K., Simstich, J., Bauch, H. A., Erlenkeuser, H., and Kroon, D.: Palaeoceanographic implications of genetic variation in living North Atlantic Neogloboquadrina pachyderma, Nature, 424, 299-302, 2003.

Bé, A. and Hutson, W.: Ecology of planktonic foraminifera and biogeographic patterns of life and fossil assemblages in the Indian Ocean, Micropaleontology, 23, 369-414, 1977.

Bé, A. W. H. and Tolderlund, D. S.: Distribution and ecology of living planktonic foraminifera in surface waters of the Atlantic and Indian Oceans, The Micropaleontology of Oceans.,Cambridge University Press, Cambridge, 105-149, 1971.

Bé, A. W. H.: Gametogenic calcification in a spinose planktonic foraminifer, Globigerinoides sacculifer (Brady), Mar.
Micropaleontol., 5, 283-310, https://doi.org/10.1016/03778398(80)90014-6, 1980.

Bemis, B. E., Spero, H. J., Bijma, J., and Lea, D. W.: Reevaluation of the Oxygen Isotopic Composition of Planktonic Foraminifera: Experimental Results and Revised Paleotemperature Equations, Paleoceanography, 13, 150-160, https://doi.org/10.1029/98pa00070, 1998.

Boyer, T., Stephens, C., Antonov, J., Conkright, M., Locarnini, R., O'Brien, T., and Garcia, H.: World Ocean Atlas 2001, Volume 2, Salinity, in: NOAA Atlas NESDIS 49,, edited by: Levitus, S., US Government Printing Office, Washington DC, USA, 165, 2002.

Carstens, J., Hebbeln, D., and Wefer, G.: Distribution of planktic foraminifera at the ice margin in the Arctic (Fram Strait), Mar. Micropaleontol., 29, 257-269, 1997.

Chapman, M. R., Shackleton, N. J., Zhao, M., and Eglinton, G.: Faunal and alkenone reconstructions of subtropical North Atlantic surface hydrography and paleotemperature over the last $28 \mathrm{kyr}$, Paleoceanography, 11, 343-357, https://doi.org/10.1029/96PA00041, 1996.

Darling, K. F., Kucera, M., Kroon, D., and Wade, C. M.: A resolution for the coiling direction paradox in Neogloboquadrina pachyderma, Paleoceanography, 21, PA2011, doi:2010.1029/2005PA001189, 2006.

Darling, K. F. and Wade, C. M.: The genetic diversity of planktic foraminifera and the global distribution of ribosomal RNA genotypes, Mar. Micropaleontol., 67, 216-238, 2008.

Deuser, W. G., Ross, E. H., Hemleben, C., and Spindler, M.: Seasonal changes in species composition, numbers, mass, size, and isotopic composition of planktonic foraminifera settling into the deep Sargasso Sea, Palaeogeography, Palaeoclimatology, Palaeoecology, 33, 103-127, https://doi.org/10.1016/00310182(81)90034-1, 1981.

Duplessy, J.-C., Blanc, P.-L., and Bé, A. W. H.: Oxygen-18 Enrichment of Planktonic Foraminifera Due to Gametogenic Calcification Below the Euphotic Zone, Science, 213, 1247-1250, https://doi.org/10.1126/science.213.4513.1247, 1981.

Elderfield, H. and Ganssen, G.: Past temperature and $\delta^{18} \mathrm{O}$ of surface ocean waters inferred from foraminiferal $\mathrm{Mg} / \mathrm{Ca}$ ratios, Nature, 405, 442-445, 2000.

Fairbanks, R. G. and Wiebe, P. H.: Foraminifera and Chlorophyll Maximum: Vertical Distribution, Seasonal Succession, and Paleoceanographic Significance, Science, 209, 1524-1526, https://doi.org/10.1126/science.209.4464.1524, 1980.

Fairbanks, R. G., Wiebe, P. H., and Bé, A. W. H.: Vertical Distribution and Isotopic Composition of Living Planktonic Foraminifera in the Western North Atlantic, Science, 207, 6163, https://doi.org/10.1126/science.207.4426.61, 1980.

Fairbanks, R. G., Sverdlove, M., Free, R., Wiebe, P. H., and Be, A. W. H.: Vertical distribution and isotopic fractionation of living planktonic foraminifera from the Panama Basin, Nature, 298, 841-844, 1982.

Field, D. B.: Variability in vertical distributions of planktonic foraminifera in the California Current: Relationships to vertical ocean structure, Paleoceanography, 19, PA2014, https://doi.org/10.1029/2003pa000970, 2004.

Fraile, I., Schulz, M., Mulitza, S., and Kucera, M.: Predicting the global distribution of planktonic foraminifera using a dynamic ecosystem model, Biogeosciences, 5, 891-911, https://doi.org/10.5194/bg-5-891-2008, 2008. 
Fraile, I., Mulitza, S., and Schulz, M.: Modeling planktonic foraminiferal seasonality: Implications for sea-surface temperature reconstructions, Mar. Micropaleontol., 72, 1-9, https://doi.org/10.1016/j.marmicro.2009.01.003, 2009a.

Fraile, I., Schulz, M., Mulitza, S., Merkel, U., Prange, M., and Paul, A.: Modeling the seasonal distribution of planktonic foraminifera during the Last Glacial Maximum, Paleoceanography, 24, PA2216, https://doi.org/10.1029/2008PA001686, 2009b.

Friedrich, O., Schiebel, R., Wilson, P. A., Weldeab, S., Beer, C. J., Cooper, M. J., and Fiebig, J.: Influence of test size, water depth, and ecology on $\mathrm{Mg} / \mathrm{Ca}, \mathrm{Sr} / \mathrm{Ca}, \delta^{18} \mathrm{O}$ and $\delta^{13} \mathrm{C}$ in nine modern species of planktic foraminifers, Earth Planet. Sc. Lett., 319-320, 133-145, 10.1016/j.epsl.2011.12.002, 2012.

Ganssen, G. M. and Kroon, D.: The isotopic signature of planktonic foraminifera from NE Atlantic surface sediments: implications for the reconstruction of past oceanic conditions, J. Geol. Soc., 157, 693-699, https://doi.org/10.1144/jgs.157.3.693, 2000.

Gill, E. C., Rajagopalan, B., Molnar, P., and Marchitto, T. M.: Reduced-dimension reconstruction of the equatorial Pacific SST and zonal wind fields over the past 10,000 years using $\mathrm{Mg} / \mathrm{Ca}$ and alkenone records, Paleoceanography, 31, 928-952, https://doi.org/10.1002/2016PA002948, 2016.

Hut, G.: Consultants' Group Meeting on Stable Isotope Reference Samples for Geochemical and Hydrological Investigations, International Atomic Energy Agency, 42, 1987.

Jensen, S.: Planktische Foraminiferen im Europäischen Nordmeer: Verbreitung und Vertikalfluss sowie ihre Verbreitung während der letzten 15,000 Jahre, Berichte Sonderforschungsbereich 313, 75, 1-105, 1998.

Jonkers, L., Brummer, G.-J. A., Peeters, F. J. C., van Aken, H. M., and De Jong, M. F.: Seasonal stratification, shell flux, and oxygen isotope dynamics of left-coiling $N$. pachyderma and T. quinqueloba in the western subpolar North Atlantic, Paleoceanography, 25, PA2204, https://doi.org/10.1029/2009PA001849, 2010.

Jonkers, L., van Heuven, S., Zahn, R., and Peeters, F. J. C.: Seasonal patterns of shell flux, $\delta^{18} \mathrm{O}$ and $\delta^{13} \mathrm{C}$ of small and large N. pachyderma (s) and G. bulloides in the subpolar North Atlantic, Paleoceanography, 28, 164-174, https://doi.org/10.1002/palo.20018, 2013.

Jonkers, L. and Kučera, M.: Global analysis of seasonality in the shell flux of extant planktonic Foraminifera, Biogeosciences, 12, 2207-2226, https://doi.org/10.5194/bg-12-2207-2015, 2015.

Jonkers, L., Buse, B., Brummer, G.-J. A., and Hall, I. R.: Chamber formation leads to $\mathrm{Mg}$ / Ca banding in the planktonic foraminifer Neogloboquadrina pachyderma, Earth Planet. Sc. Lett., 451, 177-184, https://doi.org/10.1016/j.epsl.2016.07.030, 2016.

Kim, S.-T. and O'Neil, J. R.: Equilibrium and nonequilibrium oxygen isotope effects in synthetic carbonates, Geochim. Cosmochim. Ac., 61, 3461-3475, 1997.

Kohfeld, K. E., Fairbanks, R. G., Smith, S. L., and Walsh, I. D.: Neogloboquadrina pachyderma (sinistral coiling) as Paleoceanographic Tracers in Polar Oceans: Evidence from Northeast Water Polynya Plankton Tows, Sediment Traps, and Surface Sediments, Paleoceanography, 11, 679-699, 1996.

Kretschmer, K., Kucera, M., and Schulz, M.: Modeling the distribution and seasonality of Neogloboquadrina pachyderma in the North Atlantic Ocean during Heinrich Stadial 1, Paleoceanography, 31, 986-1010, https://doi.org/10.1002/2015PA002819, 2016.
Kucera, M.: Planktonic foraminifera as tracers of past oceanic environments, Developments in marine geology, 1, 213-262, 2007.

Laepple, T. and Huybers, P.: Ocean surface temperature variability: Large model-data differences at decadal and longer periods, P. Natl. Acad. Sci. USA, 111, 16682-16687, https://doi.org/10.1073/pnas.1412077111, 2014.

Leduc, G., Schneider, R., Kim, J. H., and Lohmann, G.: Holocene and Eemian sea surface temperature trends as revealed by alkenone and $\mathrm{Mg}$ / Ca paleothermometry, Quaternary Sci. Rev., 29, 989-1004, https://doi.org/10.1016/j.quascirev.2010.01.004, 2010.

LeGrande, A. N. and Schmidt, G. A.: Global gridded data set of the oxygen isotopic composition in seawater, Geophys. Res. Lett., 33, L12604, https://doi.org/10.1029/2006GL026011, 2006.

Lombard, F., Labeyrie, L., Michel, E., Spero, H. J., and Lea, D. W.: Modelling the temperature dependent growth rates of planktic foraminifera, Mar. Micropaleontol., 70, 1-7, https://doi.org/10.1016/j.marmicro.2008.09.004, 2009.

Lombard, F., Labeyrie, L., Michel, E., Bopp, L., Cortijo, E., Retailleau, S., Howa, H., and Jorissen, F.: Modelling planktic foraminifer growth and distribution using an ecophysiological multi-species approach, Biogeosciences, 8, 853-873, https://doi.org/10.5194/bg-8-853-2011, 2011.

Loncaric, N., Peeters, F. J. C., Kroon, D., and Brummer, G. J. A.: Oxygen isotope ecology of recent planktic foraminifera at the central Walvis Ridge (SE Atlantic), Paleoceanography, 21, PA3009, https://doi.org/10.1029/2005PA001207, 2006.

Mix, A.: The oxygen-isotope record of glaciation, The Geology of North America, 3, 111-135, 1987.

Morey, A. E., Mix, A. C., and Pisias, N. G.: Planktonic foraminiferal assemblages preserved in surface sediments correspond to multiple environment variables, Quaternary Sci. Rev., 24, 925-950, https://doi.org/10.1016/j.quascirev.2003.09.011, 2005.

Mulitza, S., Wolff, T., Pätzold, J., Hale, W., and Wefer, G.: Temperature sensitivity of planktic foraminifera and its influence on the oxygen isotope record, Mar. Micropaleontol., 33, 223-240, https://doi.org/10.1016/S0377-8398(97)00040-6, 1998.

Mulitza, S., Boltovskoy, D., Donner, B., Meggers, H., Paul, A., and Wefer, G.: Temperature: $\delta^{18} \mathrm{O}$ relationships of planktonic foraminifera collected from surface waters, Palaeogeogr. Palaeocl., 202, 143-152, 2003.

Ortiz, J. D., Mix, A. C., and Collier, R. W.: Environmental Control of Living Symbiotic and Asymbiotic Foraminifera of the California Current, Paleoceanography, 10, 987-1009, 1995.

Pados, T. and Spielhagen, R. F.: Species distribution and depth habitat of recent planktic foraminifera in Fram Strait, Arctic Ocean, Polar Res., 33, 22483, https://doi.org/10.3402/polar.v33.22483, 2014.

Peeters, F. J. C. and Brummer, G.-J. A.: The seasonal and vertical distribution of living planktic foraminifera in the NW Arabian Sea, Geological Society, London, Special Publications, 195, 463-497, https://doi.org/10.1144/gsl.sp.2002.195.01.26, 2002.

$\mathrm{R}$ core team: R: A language and environment for statistical computing. R Foundation for Statistical Computing, Vienna, Austria, available at: https://www.r-project.org/, last access: January 2016.

Rebotim, A., Voelker, A. H. L., Jonkers, L., Waniek, J. J., Meggers, H., Schiebel, R., Fraile, I., Schulz, M., and Kucera, M.: Factors controlling the depth habitat of planktonic foraminifera in the 
subtropical eastern North Atlantic, Biogeosciences, 14, 827-859, https://doi.org/10.5194/bg-14-827-2017, 2017.

Rosell-Melé, A. and Prahl, F. G.: Seasonality of temperature estimates as inferred from sediment trap data, Quaternary Sci. Rev., 72, 128-136, https://doi.org/10.1016/j.quascirev.2013.04.017, 2013.

Salmon, K. H., Anand, P., Sexton, P. F., and Conte, M.: Upper ocean mixing controls the seasonality of planktonic foraminifer fluxes and associated strength of the carbonate pump in the oligotrophic North Atlantic, Biogeosciences, 12, 223-235, https://doi.org/10.5194/bg-12-223-2015, 2015.

Schiebel, R., Bijma, J., and Hemleben, C.: Population dynamics of the planktic foraminifer Globigerina bulloides from the eastern North Atlantic, Deep-Sea Res. Pt. I, 44, 1701-1713, https://doi.org/10.1016/s0967-0637(97)00036-8, 1997.

Schiebel, R., Waniek, J., Bork, M., and Hemleben, C.: Planktic foraminiferal production stimulated by chlorophyll redistribution and entrainment of nutrients, Deep-Sea Res. Pt. I, 48, 721-740, 2001.

Schmidt, G. A., Bigg, G. R., and Rohling, E. J.: Global Seawater Oxygen-18 Database - v1.21, https://data.giss.nasa.gov/ o18data/, (last access: January 2016), 1999.

Skinner, L. C. and Elderfield, H.: Constraining ecological and biological bias in planktonic foraminiferal $\mathrm{Mg} / \mathrm{Ca}$ and $\delta 180 \mathrm{Cc}$ : A multispecies approach to proxy calibration testing, Paleoceanography, 20, PA1015, https://doi.org/10.1029/2004PA001058, 2005.

Snyder, C. W.: Evolution of global temperature over the past two million years, Nature, 538, 226-228, https://doi.org/10.1038/nature19798, 2016.

Spero, H. J., Bijma, J., Lea, D. W., and Bemis, B. E.: Effect of seawater carbonate concentration on foraminiferal carbon and oxygen isotopes, Nature, 390, 497-500, 1997.
Spero, H. J., Mielke, K. M., Kalve, E. M., Lea, D. W., and Pak, D. K.: Multispecies approach to reconstructing eastern equatorial Pacific thermocline hydrography during the past 360 kyr, Paleoceanography, 18, 22-21, 2003.

Steinke, S., Chiu, H.-Y., Yu, P.-S., Shen, C.-C., Löwemark, L., Mii, H.-S., and Chen, M.-T.: $\mathrm{Mg} / \mathrm{Ca}$ ratios of two Globigerinoides ruber (white) morphotypes: Implications for reconstructing past tropical/subtropical surface water conditions, Geochem. Geophys. Geosys., 6, Q11005, https://doi.org/10.1029/2005gc000926, 2005.

Stephens, C., Antonov, J., Boyer, T., Conkright, M., Locarnini, R., O'Brien, T., and Garcia, H.: World Ocean Atlas 2001, Volume 1, Temperature, in: NOAA Atlas NESDIS 49, edited by: Levitus, S., US Government Printing Office, Washington DC, USA, 167, 2002.

Tolderlund, D. S. and Bé, A. W. H.: Seasonal distribution of planktonic foraminifera in the western North Atlantic, Micropaleontology, 17, 297-329, 1971.

Waelbroeck, C., Mulitza, S., Spero, H., Dokken, T., Kiefer, T., and Cortijo, E.: A global compilation of late Holocene planktonic foraminiferal $\delta^{18} \mathrm{O}$ : relationship between surface water temperature and $\delta^{18} \mathrm{O}$, Quaternary Sci. Rev., 24, 853-868, 2005.

Wolfteich, C. M.: Sattelite-derived sea surface temperature, mesoscale variability, and foraminiferal production in the North Atlantic, MSc, MIT and WHOI, Cambridge, MS, 91 pp., 1994.

$\mathrm{Wu}$, G. and Berger, W. H.: Planktonic foraminifera: Differential dissolution and the Quaternary stable isotope Record in the west equatorial Pacific, Paleoceanography, 4, 181-198, https://doi.org/10.1029/PA004i002p00181, 1989.

Zaric, S., Donner, B., Fischer, G., Mulitza, S., and Wefer, G.: Sensitivity of planktic foraminifera to sea surface temperature and export production as derived from sediment trap data, Mar. Micropaleontol., 55, 75-105, 2005. 